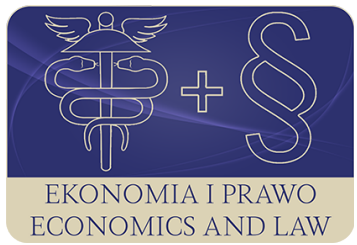

EKONOMIA I PRAWO. ECONOMICS AND LAW

Volume 19, Issue 1, March 2020

p-ISSN 1898-2255, e-ISSN 2392-1625

www.economicsandlaw.pl

EKONOMIA I PRAWO

ORIGINAL ARTICLE

received 13.07.2019; revised 11.01.2020; accepted 31.03.2020

Citation: Krzyminiewska, G. (2020). Ethical dilemmas of the silver economy. Ekonomia i Prawo.

\title{
Ethical dilemmas of the silver economy
}

\section{GRAŻYNA KRZYMINIEWSKA}

Poznań University of Economics and Business, Faculty of Economics, Department of Sociology and Business Ethics, al. Niepodległości 10, 61-875 Poznań, Poland

๑razyna.krzyminiewska@ue.poznan.pl

(D) orcid.org/0000-0002-1573-3771

\begin{abstract}
Motivation: The silver economy means the existing and emerging economic opportunities caused by the ageing population. It creates a number of dilemmas encourages its broader analysis in view of the emerging ethical problems.

Aim: The aim of the article is to present ethical problems arising in connection with the aging of the population. The article hypothesizes that the development of individual activities undertaken in the field of the so-called 'silver economy' repeatedly violates the ethical rules of social relations, which may contribute to reducing the quality of life and social status of senior citizens. The implementation of the silver economy, related to the rejection of biases and stereotypes concerning the elderly, is the essence of the problem analysis. The ethical dilemmas mentioned in the title indicate the need to reflect on the problem, whose solution presents a difficult choice between two equally important perspectives: the personalized, pro-senior citizen approach; and a pragmatic approach to alleviating the impacts of an ageing society on society overall. The problem is considered with respect to various fields of activity of the silver economy, concentrated around the silver industry, social innovation and gerontechnology.

Results: The development of the silver economy will be one of the expected megatrends in the economy. The activities of silver industries, social innovation and gerontechnology are a condition to increase the level and quality of life of the older generation. The silver economy is a major stimulus for development, provided that it is based on ethical principles that promote social and economic inclusion, as well as on counteracting the negative consequences of stereotyping, ageism and social exclusion. The analyzes carried out indicate that the ethical approach to the development of the 'silver economy' has not been sufficiently considered to date.
\end{abstract}

Keywords: ethics; ethical dilemmas silver economy; ageing population JEL: Al3 


\section{Introduction}

The global population aged 60 years or over numbered 962 million in 2017, more than twice as large as in 1980 when there were 382 million of the elderly worldwide. The number of elderly people is expected to double again by 2050, when it is projected to reach nearly 2.1 billion. The process of population ageing is most advanced in Europe and in Northern America. In 2050, the elderly is expected to account for 35 per cent of the population in Europe, 28 per cent in Northern America, 25 per cent in Latin America and the Caribbean, 24 per cent in Asia, 23 per cent in Oceania and 9 per cent in Africa (United Nations, 2017). The unprecedented growth of the elderly in the world population implies a number of legal, technological, social and economic problems and ethical problems associated with them, which currently are not sufficiently considered.

The article focuses on the ethical aspects of the silver economy, recognising that their analysis and careful consideration is important for the process of its proper development, and therefore important to preventing (minimise) the threats to responsible development. The article uses the following order of analysis: The literature review was indicated including the definition of the silver economy applied by the European Union and the Organisation for Economic Cooperation and Development; the analysis of various ethical aspects related to the ageing of the population and the development of the silver economy was conducted and subsequently the adopted research methodology was characterised. Additionally, issues requiring a broad scientific discussion were identified (discussions). The final part of the work contains conclusions.

\section{Literature review}

\subsection{The general concept of the silver economy}

The subject literature specifies silver economy in accordance with definition primarily decided on by the OECD and the European Union, which accepted a certain point of view in the adopted documents and development strategies. The European Commission (2009) defines the silver economy as the existing and emerging economic opportunities that develop as a result of the increasing government and consumer spending, as well as of the specific needs of people aged 50 years and older resulting from the ageing of the population. On the other hand, the silver economy is recognised by the OECD et al. (2014) as the silver production, or the i.e. that produces and delivers products and services targeted at the elderly, shaping the environment in which people aged over 60 cooperate and achieve successes in the workplace, engage in innovative projects, help in the development of the market as customers and lead healthy, active and productive lives. In the case of the European Union, thinking in terms of using the potential of people and adequate policies in favour of the activity 
of the elderly, which will allow increasing the period of professional activity and promoting ageing while maintaining social inclusion, is a significant issue in the development of the silver economy. Intergenerational solidarity, aimed at strengthening social cohesion, inclusion and social participation throughout a person's life by creating opportunities as well as access to services and political, social, recreational and cultural activities, is the key. Following the social policy of the European Union, the emphasis will be placed on recognising the value of all age groups and their contribution to society, thus promoting a positive perception of all generations.

Broad opportunities to develop the silver economy through silver industries, including their innovativeness and competitiveness which give rise to a possibility to transform demographic threats into chances of development, are identified both by the OECD and the UE. Creation of a new paradigm of the modern world development, which imposes an obligation to develop a system of thinking, which may result in moral principles to develop the silver economy, constitutes the essence of the process. The silver economy should be considered as a holistic concept covering various economic and social aspects. The silver economy is not only the production of goods and services dedicated to senior citizens but also a wide range of activities. According to Enste et al. (2008, pp. 330-331), the areas in which the silver economy may stimulate the development of market sectors directly or indirectly related to the ageing of the population are, among others:

- information technologies (IT) in health care;

- flat adaptation and services that make life easier, based primarily on IT;

- independent life based on the growing use of IT;

- areas which are gerontologically significant for the health economy, including medical technologies and e-health, vision and hearing technologies, prosthetics and orthopaedics;

- education and culture as the answer to the desire for development and leisure time management;

- IT and media combined with medicine, promoting independence and safety;

- service robotics and the promotion of independent life in the case of elderly people with severe diseases;

- mobility and promotion of its constituents, e.g. road traffic safety;

- leisure, travel, culture, communication and entertainment;

- fitness and wellness as the response to the raising awareness of the healthy lifestyle;

- clothing and fashion as a manifestation of the desire for social integration;

- services facilitating the day-to-day functioning and other housework;

- insurance primarily related to the forms of risk specific to the elderly;

- financial services, particularly with regard to protecting capital, preserving assets and preventing loss of savings. 
Scheme 1. indicates various areas of the activity of the silver economy arranged in silver industries, social innovations and gerontechnology. Each of these areas creates different ethical dilemmas.

\subsection{Ethical aspects of silver industries}

Two important areas of activity may be identified within silver industries, which define the relationship between an ageing society and business. The first one involves the silver production, i.e. the production of goods and services intended for senior citizens and meeting their specific and age-related needs - their psychophysical health as well as the status of household (Zsarnoczky, 2016a, p. 107 ), while the second is related to the area of the professional activity of elderly workers.

Silver production is an area whose goal of is to respond to the changing consumer market with a growing number of ageing people. A great number of economic operators may not, however, be interested in the production and distribution of products for the elderly, as they may consider the provision of various services for seniors as unattractive for business. There is a risk that this market may be perceived as the 'second quality market' by some manufacturers. This means that in many areas attention will be focused on wealthy consumers, for whom the production (and services) of a luxurious nature is planned. By way of example - according to Enste et al. (2008, pp. 330-331), clothing and fashion should be included within the silver industry and their appropriate design should be perceived as a manifestation of the desire for social integration. There is, however, no doubt that the attention of the modern world's designers and manufacturers is focused on the needs (and the creation) of the younger generation. Clothing and shoes are to a large extent addressed to slim and tall people and frequently are to emphasize sexuality. The non-standard figures of the elderly, who need their clothes and shoes to be comfortable, light, but also elegant, are taken into account by this production department to a much lesser extent. The very essence of the problem is a need for social inclusion, where appearance, including clothing, does not stigmatize nor does it the elderly or negatively distinguishes them from the surrounding, reinforcing stereotypes that the elderly is poor and scruffy. Ageing is frequently a source of anxiety (also due to a decrease in the symbolic value of the body), and increasing the aestheticisation of everyday life may positively reduce the risk of failure in human relationships, facilitate the process of social interaction and reduce inequalities (Schilling, 2010, p. 279).

The issues regarding various services, including financial ones, may also be included within silver industries. It is, therefore necessary to adopt a new financial service strategy aimed at the elderly. The key challenge is to protect capital, preserve property and prevent the loss of savings of the elderly, who frequently become the target of dishonest practices. The proper organization and management of this area become the key to securing the financial future of elderly 
people and reducing the impact of the demographic burden. Currently, there are no general, long-term projects of financial institutions related to the provision of services for an ageing society and the counteracting of financial exclusion of the elderly, and yet the ageing processes of the society will significantly strengthen the importance of the older group of consumers of financial services, which will become a trend.

Senior citizens as potential customers of financial institutions constitute a very sensitive, difficult segment when it comes to making financial decisions. This results from two issues: people of the oldest age groups with the least experience in markets and financial instruments, and at the same time with a low level of trust, may not be interested even in the most favorable offers for them, but also, due to the decrease in cognitive skills with age, they will not be able to make conscious decisions. Unfortunately, the abuse of elderly people was reported to have taken place in financial institutions, where weaker analytical skills of the elderly were used to encourage them to purchase products more profitable for the organization than for the senior.

The second area of silver industries is to support older workers, perhaps by countering ageism, creating a friendly work-space for older workers, and strengthening the role of education. Ageism is a manifestation of social prejudice that marginalizes or explicitly excludes older persons from the mainstream of social and economic life. The glorification of youth, which is commonly encountered in the modern world, devalues the experience of the elderly, their commitment and often higher loyalty to the employer than the younger generation's. This kind of social bias is unacceptable not only for ethical reasons, but it is also economically and socially irrational - since the valuable human capital, which can also contribute to social and economic development, is wasted.

Therefore, it is necessary to assume that a cultural change related to the necessary changes in the mentality of all generations is crucial for the success of senior economy. This regards the elevation of the so-called 3rd age as active and valuable both among the senior citizens, who withdraw from the mainstream society due to age (and not necessarily medical condition), and younger generations, frequently reluctant or hostile towards the growing population of elderly people. The elderly, as a social category, much more often than in previous decades are refusing to 'stay in the shadows', so it becomes necessary to use the potential of the elderly and their growing activity, develop intergenerational communication, change the image of the elderly as poor, clumsy and - unnecessary and actively use their knowledge, experience and skills. This means overcoming intergenerational prejudices and stereotypes and creating a social order friendly for all generations. Lifelong education, which is one of the foundations of the development of the modern state, mental acceptance for the development of knowledge and skills of employees of all ages, is a necessary condition. Conditions of the current labour market make both sides of this process - employers and employees - see no point in investing, for example, in the trainings for senior employees as economically unreasonable due 
to the rapid completion of their careers in some countries. According to Turek (2015, p. 169): 'at present social sciences have an extensive empirical base for opinions and stereotypes regarding the age of an employee (...) negative stereotypes concerning the ability and productivity of older workers affect the decisions and activities of employers in terms of management practices and lead to discriminatory behaviour'. These activities are evidently incompatible with the idea of social responsibility of business. To reduce this unfavorable phenomenon, it is necessary to perceive it through the activities that reduce the consequences of unequal access to education for different groups of employees or actions that support the elderly who frequently become the disfavored group on the labour market. Such activities may certainly bring significant benefits, because supporting the processes of knowledge and skills management will raise the value of human capital and social development, while undoubtedly being an added value for the organization and, the local environment, and will promote the integration of older persons.

\subsection{Social innovations and gerontechnology dilemmas}

The concept of social innovation refers to the creation of new strategies, concepts and organisational forms that are aimed at meeting the needs, that have emerged especially in the borderline of various sectors of the social system (O'Sullivan et al., 2010). 'By way of example, they are the innovations emerging at the meeting point of cooperation or competition between the public and commercial sectors, the commercial and the non-governmental sectors, the commercial and the social economy or the informal sectors. Such innovations have social goals and means and they create new social relations and cooperative links between individuals, groups and organisations. Creative use of new technologies for the elderly and by the elderly, new models of care, including combinations of formal and informal forms of support, creation of spaces, which contribute to building the intergenerational relationships, and mobilisation of the trust networks (social support of communities, self-help groups) are among the examples of such innovations' (Klimczuk, 2016, p. 44). Activities of care farms (also referred to as social agriculture), the purpose of which is to combine day care or long-term care services with the elements of agricultural production and animal husbandry, are an excellent example of such initiatives (Krzyminiewska \& Pondel, 2018). A care farm, in accordance with the adopted definition, is a form of support in the field of social protection and inclusion implemented by an enterprise engaged in agricultural activity. They have been successfully implemented for many years in European countries such as Italy, France, Norway, Belgium, Austria, Germany and the UK, as well as in the United States. The services provided by such farms are not only offered to the elderly but also to disabled people (including those with intellectual disabilities), victims of occupational burnout, or depression, and people diagnosed with autism. On the other hand, gerontechnology is a new scientific and research perspective 
on the science of technologies created for an ageing society. Gerontechnology is related to the design of electronic means of everyday life, such as solutions for remote work, sensors, alarms, devices for improving hearing, smell and vision, bathroom systems, as well as smart homes. Undoubtedly, healthcare is the field, which is affected by technological processes to the greatest extent, and some of the most rapidly developing areas of innovative technologies are telemedicine and tele-optics. However, technology, artificial intelligence in particular, is associated with numerous ethical dilemmas. Firstly, the most important thing is to ensure that technology is not used to stigmatise senior citizens. Since special products are created or interactive devices monitoring the lives of seniors (e.g. portable GPS systems that allow real-time monitoring, which are dedicated to people in the early stages of dementia) are included in their lives, they may increase the elderly's sense of dependence on other people and technologies, arouse a sense of marginalisation and exclusion and increase fears. Unfortunately, the ethical side of this phenomenon is no more transparent than the question of ethical consequences of the participation of artificial intelligence in our lives as well as the replacement of personal relationships and social ties with impersonal technology. According to many researchers, the development of gerontology may entail the dehumanisation of life, where contacts with a 'living human' will be replaced by a personalised robot. This is an extremely difficult area of consideration, since, on the one hand, these type of technologies, referred to as 'civilisation prostheses', contribute to improving the quality of life of the elderly and support their independence, but on the other - they may deepen social isolation and a sense of loneliness. The problem lies in the atomisation of ties and social relations as well as in weakening the family relationships caused by the transformations characteristic of the modern world. In a large scale, there is a problem of elderly people's loneliness and lonely death (in Japan this phenomenon is referred to as a 'quiet death' - 'kodokushi'). The lonely old age, which affects a wider population of the elderly around the world, indicates a strong weakening of ties among humans. Works on humanoid robots give hope for possibilities to provide dependent seniors with round-the-clock care, but they raise questions regarding the ethical boundaries of replacing interpersonal relationships with them. The quote by Aristotle "man is by nature a social animal' clearly indicates that a man, being a biological unit, needs another person to be a complete human being. Living alone does not correspond to our nature because we need relationships with others to function properly. This translates into the quality of our life, including our health, which in turn is greatly deteriorated by social isolation.

Bearing this in mind, particular attention should be paid to the creation of organisational forms associated with the arrangement of spaces that facilitate building intergenerational relations and the mobilisation of the trust networks. 


\section{Methods}

The content of this article is in line with economic and social analysis, using the sociological and economic achievements, and was based on the existing sources and the results of own research. Desk research and descriptive analysis were used in the presentation of the issues addressed. The research method has been chosen on the basis of a review of this area, which highlighted a lack of analyses of this type, and a lack of descriptive statistical data.

Documents of international organizations such as the European Union and OECD (for a different time horizon) were analyzed. Study of the subject of the literature critical review was carried out and the secondary sources were used.

\section{Results}

Development of the silver economy, according to the forecasts of major international organizations and research centers, will be one of the expected megatrends in the economy (Deloitte, 2018). The silver economy is (will be) implemented both in the area of meeting the needs of elderly customers-consumers, increasing the activity of the elderly on the labour market, given the increased life expectancy and unsatisfactory social security. The first issue is that of the definition of the threshold of 'senior' or 'old' age, which is currently set as relatively early. As life expectancy and the quality of life increases, an 'old age' threshold of 55 or 60 years of age would appear to be rather premature. Discrepancies that arise around the issue of termination of professional activity indicate that flexibility in the employment of older people and treating seniors as a heterogeneous group should be considered. Seniors differ in many ways - both in terms of their general socioeconomic status (financial status, social status, social and cultural capital possessed, gender, physical and mental condition), as well as diversity due to age (Zsarnoczky, 2016b).

A wide range of activities of silver industries, social innovation and gerontechnology is a condition to increase the level and quality of life of the older generation. The silver economy is a serious stimulus for development, provided that it is based on axiological assumptions of social development in accordance with the people-centred development approach, assigning subjectivity to the individual and the group to the fullest extent possible. The development of the silver economy is possible on the basis of ethical rules that promote social and economic inclusion, and counteract the negative consequences of stereotyping, ageism and social exclusion. Scheme 2 shows the main ethical problems associated with the development of silver economy.

The indicated ethical problems related to the 'silver economy' do not cover their broad spectrum. Undoubtedly, we are dealing with a lack of dissemination of ethical standards regarding activities undertaken within the silver economy. The previous ones - mainly those related to corporate social responsibil- 
ity — are not always adequate to the newly arising problems of aging society, and mainly related to gerontechnology.

\section{Conclusion}

The assumptions of the silver economy aim at responding to the advanced ageing processes. The introduction of the silver economy is to enable the transformation of demographic problems into opportunities for development, and the development strategy, which takes into account the needs of the ageing population, contributes to improving the quality of life not only of the elderly, but also of all members of the population. This is possible as long as the postulate of ethical social development will be implemented.

\section{References}

European Commission. (2009). Communication from the Commission to the European Parliament, the Council, the European Economic and Social Committee and the Committee of the regions: dealing with the impact of an ageing population in the EU (2009 Ageing Report) (COM(2009) 180).

United Nations. (2017). World population ageing 2017. Retrieved 10.07.2018 from http://www.un.org.

Deloitte. (2018) 6 megatrendów będzie miato największy wptyw na ksztatt globalnej gospodarki. Retrieved 18.10. 2018 from https://www2.deloitte.com.

Enste, P., Naegele, G., \& Leve, V. (2008). The discovery and development of the silver market in Germany. In F. Kohlbacher, \& C. Herstatt (Eds.), The silver market phenomenon: business opportunities in an era of demographic change. Berlin: Springer. doi:10.1007/978-3-540-75331-5_22.

Klimczuk, A. (2016). 'Silver economy' models in the European Union in the comparative approach: an attempt to introduce discussion. Problemy Zarządzania, 59(2/1). doi:10.7172/1644-9584.59.3.

Krzyminiewska, G., \& Pondel, H. (2018). Care farms in the strategy of the multifunctional development of rural areas. In Jedlicka P., Maresova P., \& Soukal, I. (Eds.), Hradec Economic Days 2018. Kralove: University of Hradec Kralove.

OECD, University of Oxford, \& Global Coalition for Ageing. (2014). The silver economy as a pathway for growth: insights from the OECD-GCOA expert consultation. Retrieved 10.07.2018 from https://www.oecd.org.

O’Sullivan, C., Mulgan, G., \& Vasconcelos, D. (2010). Innovating better ways of living in later life: context, examples and opportunities. The Young Foundation Working Paper, May.

Schilling, C. (2010). Socjologia ciata. Warszawa: PWN.

Turek, K. (2015). Znaczenie wieku na rynku pracy: model relacji pomiędzy pracownikiem i pracodawcą. Studia Socjologiczne, 2(217).

Zsarnoczky, M. (2016a). Innovation challenges of the silver economy. Vadyba Journal of Management, 1(28). 
Zsarnoczky, M. (2016b). The new hope for the EU: silver economy. In W. Miczorek (Ed.), Building bridges: cities and regions in a transnational world. Graz: RSA.

\section{Acknowledgements}

Author contributions: author has given an approval to the final version of the article.

Funding: this research was funded by the Poznań University of Economics and Business, Faculty of Economics, Department of Sociology and Business Ethics statutory sources.

Note: the results of this study were presented at 8th International Scientific Conference: Contemporary Economic Problems 'Social-economic problems in the era of globalization: theory and practice' (May, 22, 2019, Torun, Poland). 


\section{Appendix}

Scheme 1 .

Areas of activities of the silver economy

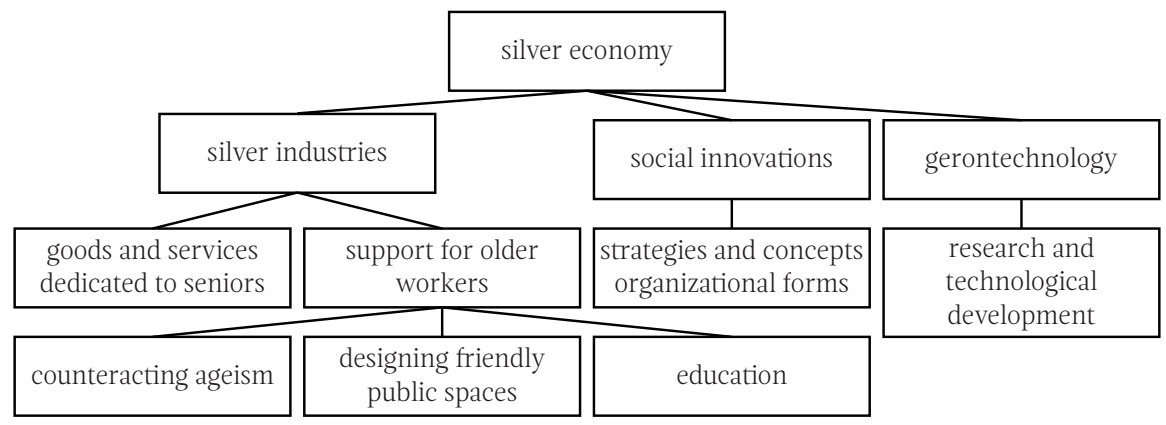

Source: Own preparation.

\section{Scheme 2.}

Areas of ethics problems of the silver economy

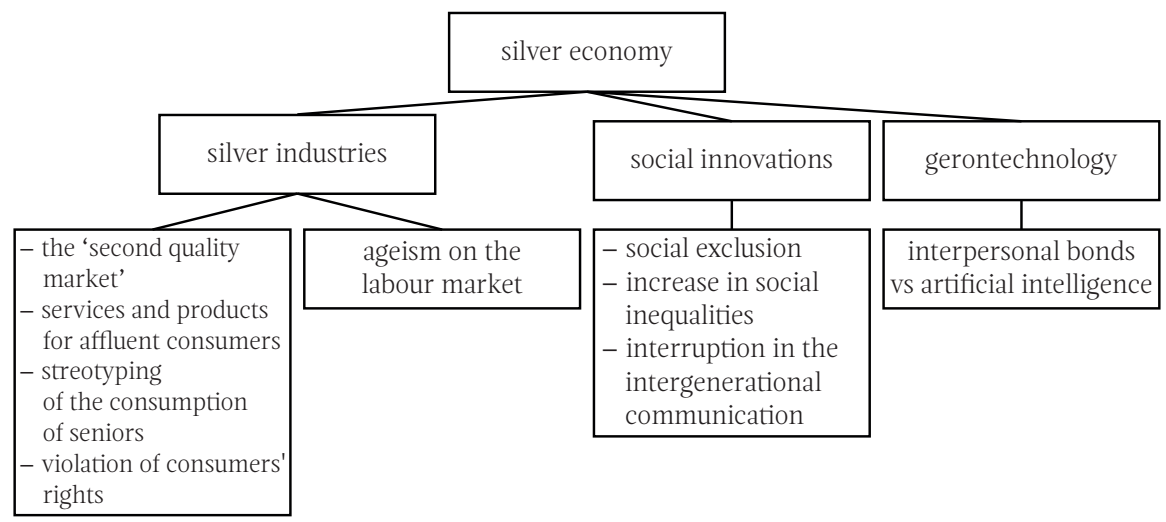

Source: Own preparation. 
